\title{
Roberto Dan. From the Armenian Highland to Iran. A Study of the Relations between the Kingdom of Urartu and the Achaemenid Empire
}

\section{Rémy Boucharlat}

\section{(2) OpenEdition \\ 1 Journals}

\section{Édition électronique}

URL : http://journals.openedition.org/abstractairanica/46255

DOI : $10.4000 /$ abstractairanica.46255

ISBN : 1961-960X

ISSN : 1961-960X

Éditeur :

CNRS (UMR 7528 Mondes iraniens et indiens), Éditions de l'IFRI

\section{Référence électronique}

Rémy Boucharlat, «Roberto Dan. From the Armenian Highland to Iran. A Study of the Relations between the Kingdom of Urartu and the Achaemenid Empire », Abstracta Iranica [En ligne], Volume 37-38-39 | 2018, document 79, mis en ligne le 30 décembre 2018, consulté le 29 septembre 2020. URL : http:// journals.openedition.org/abstractairanica/46255; DOI : https://doi.org/10.4000/abstractairanica. 46255

Ce document a été généré automatiquement le 29 septembre 2020.

Tous droits réservés 


\title{
Roberto Dan. From the Armenian Highland to Iran. A Study of the Relations between the Kingdom of Urartu and the Achaemenid Empire
}

\author{
Rémy Boucharlat
}

\section{RÉFÉRENCE}

Roberto Dan. From the Armenian Highland to Iran. A Study of the Relations between the Kingdom of Urartu and the Achaemenid Empire. Rome: Scienze e Lettere/ISMEO, 2015, XVIII-177 p., 45 pl., bibliographie, index. (Serie Orientale Roma, n.s. 4)

1 RD, archéologue spécialiste du Caucase méridional et plus particulièrement de la période urartéenne (grosso modo ixe-viie s. av. J.-C.), s'attaque à la question des origines des éléments qui seraient urartéens dans l'art et de l'architecture achéménide, des comparaisons qui reposent sur des comparaisons assez superficielles. L'A. montre que l'Urartu ne joue pas un rôle particulier dans la formation de l'architecture achéménide (rappelons que ce royaume disparaît plus d'un demi-siècle avant Cyrus) mais qu'il a été une source d'influence parmi beaucoup d'autres, originaires de différentes contrées (Grèce l'Asie Mineure, Assyrie, Egypte, etc.) et même de régions proches de l'ancien Urartu avec lequel on les confond parfois.

Le chapitre 1, principalement historique, est consacré à la fin du royaume d'Urartu puis la région durant la supposée époque mède, enfin ces mêmes territoires dans l'empire perse. Le chapitre 2 forme le corps de l'étude, analysant les possibles relations entre l'architecture de cette région et celle de l'époque perse dans les résidences royales, à partir des éléments connus en Urartu, dont les fameux temples-tours, à salle unique aux murs renforcés de contreforts aux angles. Il est commun d'en faire l'origine des tours de Pasargades et Naqsh-i Rustam. Transmission directe ou indirecte, il n'est pas 
possible de trancher, tout en observant que les premières avaient un espace religieux au rez-de-chaussée et que seule la partie inférieure était en pierre, tandis que les tours achéménides, entièrement en pierres taillées, sont pleines et comportent seulement une petite chambre en hauteur. De même, un rapprochement direct des salles hypostyles du territoire de l'Urartu avec les salles achéménides néglige les constructions à poteaux des sites «mèdes " du Zagros central. Ces dernières sont en bois comme en Urartu et reposent sur de modestes bases en pierre non travaillées, tandis que l'Urartu connaît les bases en pierre, parfois inscrites. Les fenêtres aveugles constituent un élément commun aux architectures urartéenne et achéménide, de même que les couronnements de merlons à trois degrés; en revanche il est difficile de rapprocher les chambres rupestres de l'Urartu des tombes des rois perses.

3 Le domaine de la maîtrise de l'eau dans laquelle les Urartéens ont excellé, mais les Assyriens également; c'est est un domaine de comparaison qui pourrait être prometteur lorsque l'on connaîtra mieux les réalisations de l'époque achéménide, tels que les réseaux de canaux et les grands barrages.

4 Avec une copieuse bibliographie de 15 pages (chapitre 3) et un index détaillé, ce livre constitue un ouvrage très bien informé, nuancé dans ses analyses et ses conclusions, qui sera utile à ceux qui étudient l'art achéménide, et pas seulement la question de ses origines.

\section{AUTEURS}

\section{RÉMY BOUCHARLAT}

UMR 5133 CNRS-Université de Lyon 